\title{
European map of prevalence rates of elder abuse and its impact for future research
}

\author{
Liesbeth De Donder • Minna-Liisa Luoma $\cdot$ Bridget Penhale $\cdot$ Gert Lang • \\ Ana J. Santos - Ilona Tamutiene - Mira Koivusilta - Anna Schopf • \\ José Ferreira Alves · Jolanta Reingarde $\cdot$ Sirkka Perttu • Tiina Savola • \\ Dominique Verté
}

Published online: 20 May 2011

(C) Springer-Verlag 2011

\begin{abstract}
This article aims to map existing prevalence research on abuse and neglect of older people and to provide a critical overview of existing methodologies, which have been adopted to survey the prevalence rates of abuse against elders. This article is part of the prevalence study of Abuse and Violence against Older Women (AVOW) study, which was conducted in five European countries (Austria, Belgium, Finland, Lithuania, and Portugal). The article provides an overview of the state of the art of prevalence data, survey designs and methods, instruments and results in Europe. Therefore, this draws on an extensive literature search and qualitative content analysis, which was conducted as an early part of the AVOW study. Results indicate that some EU countries have a rich history of prevalence research, whereas other countries have just begun to tackle this aspect of research on of elder abuse. One of the lacunae concerns reliable numbers on the prevalence rates of elder abuse. Research about where, when and
\end{abstract}

Responsible editor: H. W. Wahl.

L. De Donder $(\bowtie) \cdot$ D. Verté

Department of Educational Sciences, Vrije Universiteit Brussel, Pleinlaan 2, 1050 Brussels, Belgium

e-mail: 1dedonde@vub.ac.be

M.-L. Luoma · M. Koivusilta

Department of Living Conditions, Health and Wellbeing,

National Institute for Welfare and Health (THL), P.O. Box 30,

00271 Helsinki, Finland

B. Penhale

School of Nursing and Midwifery, Faculty of Health, University of East Anglia, Edith Cavell Building, Norwich NR4 7TJ, UK

G. Lang - A. Schopf

Research Institute of the Red Cross, Nottendorfer Gasse 21,

1030 Vienna, Austria how often elder abuse occurs, is inadequate and inconsistent. Data in some cases are based on professionals' reports rather than on information from older people themselves. Surveying elders about such a sensitive topic, however, implies the need for an adequate research instrument (questionnaire) and research design, and an adapted data collection method. In conclusion, substantial attention is paid to outlining possible guidelines for future research.

Keywords Elder abuse $\cdot$ Violence $\cdot$ Neglect $\cdot$ Older people $\cdot$ Prevalence

\section{Introduction}

The World Health Organisation (WHO) and the International Network of the Prevention of Elder Abuse (INPEA) 
have recognised the abuse of older people as a significant global problem (Bennett et al. 2002). Elder abuse is a human rights violation resulting in suffering and decreased quality of life (Hudson 1991). Moreover, it is an infringement of Article 25 of the EU Charter of Fundamental Rights, which recognises and respects the rights of older people to lead lives of dignity and independence, and to participate in social and cultural life (EU 2000). Notwithstanding this recognition, the issue of elder abuse does not yet emerge as a major theme in research, nor does it in the study of policymakers. The rapid ageing of society, however, means that there will be a growing population of older people living at home and the most vulnerable of them will be dependant on care or assistance, and may need to be protected from violence and abuse. The potential vulnerability of elder people to violence is not always socially visible and has not been adequately considered in the public sphere (Strümpel and Hackl 2008).

Sharing the knowledge about different countries in Europe will contribute to tackling elder abuse (Penhale 2006). Therefore, the aim of this article is to map existing prevalence research about abuse and neglect of older people and to provide a critical overview of existing methodologies, which have been adopted to survey the prevalence of abuse against elders in all European countries. This article intends to give an overview of the state of the art of prevalence data, research designs, methods and instruments across Europe.

Research on elder abuse lacks appropriate theoretical and conceptual clarity in the literature. Few researchers have clearly defined the 'elder abuse' concept and that deficit manifests in its operationalisation within research (and practice). Therefore, this article will begin with a literature review to delineate a clear definition of elder abuse, and will thereby distinguish several dimensions, types and forms of elder abuse. Next, we will discuss the research methodology utilised in this study. Further, in the "Results" section, we describe our main findings concerning the extent of elder mistreatment in Europe, statistical data and current methodologies. Issues such as sampling, regional scope, age of respondents, research design, data collection and the measurement instrument will be discussed. In conjunction, the operationalisation, reliability and validity of the used survey instruments used are examined. Finally in our conclusion, we discuss the main findings and develop a number of implications and recommendations for future prevalence studies.

\section{Definition}

According to the WHO (2002b), elder abuse was described for the first time in a British scientific publication in the year 1975 using the term 'granny battering' (Baker 1975;
Burston 1975). However, the definition of elder abuse is a complex phenomenon and the definition is related to ideological and philosophical values. Different scientists, policymakers and professionals use different definitions of elder abuse. In some ways violence and abuse are not so easy to conceptualise as the boundaries are somewhat fluid and the beginning of abusive actions are often difficult to determine (Hörl and Spannring 2001).

Definitions vary from author to author, even within research studies, depending on the different perspectives of their research programs and paradigms (e.g. victims' perspectives vs. caregivers' perspectives). As a consequence of these different approaches, there are certain inconsistencies in the concepts and there is a lack of agreement on a common definition (Penhale 2008). Summarising, definitions have paid attention to the types of abuse (e.g. physical, psychological, neglect and so forth), who does the abusing (perpetrator descriptions), who suffers the abuse (victim descriptions), the relationship between the victim and the perpetrator (mutual trust and dependency of the victim), the intention (intentional or unintentional), whether the mistreatment may be an act of commission (abuse) or omission (neglect) and where it happens (e.g., domestic violence or institutional settings).

Nevertheless, one definition arises in a number of studies. This specific definition of elder abuse was developed by the UK's Action on Elder Abuse (1995, p. 11) and subsequently adopted by the International Network for Prevention of Elder Abuse (INPEA) and the WHO (2002a, p. 3) in their Toronto declaration: elder abuse is 'a single or repeated act, or lack of appropriate action, occurring within any relationship where there is an expectation of trust which causes harm or distress to an older person'.

\section{Different types of elder abuse}

Abusive behaviours take various forms. In the literature, elder abuse has often been categorised as physical, psychological, sexual and financial abuse and neglect (WHO 2002a). These categories remain important, but these definitions require a cultural context, and other issues could be included within the overall framework, as found in research across different contexts (WHO 2002a). Giving this some initial impetus, for the purposes of this article, we will also include violation of the personal rights of an older person as a form of elder abuse.

\section{Physical abuse}

This category refers to actions carried out with the intention of causing physical pain or injury to a (vulnerable) older person. Examples can be being pushed, grabbed, slapped, hit with an object, hitting, striking with an object, 
administering too much tranquilising or neuroleptic medication (cf. WHO 2002a).

\section{Psychological/emotional/verbal abuse}

This form of violence describes all actions inflicting mental pain, anguish or distress on a person through verbal or nonverbal acts. Examples can be the use of abusive language, oppression, manipulation, bullying, blackmail, shouting, threats, humiliation, isolating the older person or infantilising the person (cf. WHO 2002a).

\section{Sexual abuse}

This form of violence refers to non-consensual sexual contact of any kind (e.g. unwanted intimacy, touching in a sexual way, rape, undressing in front of the victim, sexually slanted approaches). Sexual abuse is difficult to recognise because it often happens under circumstances that conceal the violent and abusive character of the action (HagemannWhite 2001). Sexual abuse can also be described as 'terror in intimate relations' that has the intention to control the partner/a person and is only one-sided (Görgen et al. 2009, p. 46).

\section{Financial/material abuse or exploitation}

This form of violence describes all actions of illegal or improper use of an elder's funds, property or assets (WHO 2002a). Examples are problems with powers of attorney, swindling, disappearance of money or goods, obstruction in managing one's own money, legacy hunting and extortion.

\section{Neglect}

This type of abuse deals with the refusal or failure by those responsible to provide essential daily living assistance and/ or support such as food, shelter, health care or protection for an older person. This bears resemblance to the term abandonment, neglect in its most extreme form: the desertion of a vulnerable elder by anyone who has assumed the responsibility for care or custody of that person (WHO 2002a). Furthermore, the literature differentiates between active and passive neglect: passive neglect is present when for instance malnutrition or the development of a decubitus occurs, often through an unintentional failure to provide care. Active neglect is described as refusal of cleaning, care, medication and nutrition (e.g. Dieck 1987) in the knowledge that harm is likely to occur as a result. Some authors also use the term of derailed or misspent care: the unintentional neglect in a context of care, when the amount of needed care exceeds the capacity of the caregiver to provide this (Bakker et al. 2000).
Violation of the personal rights

This last category is not often included in discussions on theoretical concepts and research practices. The UK Department of Health and Home Office (2002, p. 9) considers abuse as 'a violation of an individual's civil or human rights by any other person or persons' in relation to guidance on the abuse of vulnerable adults. Narrowing this definition down, we could also understand the infringement of personal rights as elder abuse. This includes, for instance, the violation of privacy, the right to autonomy, freedom, refusing access to visitors, isolating the elder or reading or withdrawing mail. This is closely intertwined with a call to incorporate disrespect into the framework of elder abuse. Qualitative interviews have revealed this topic to be of major importance in a study that included older people's perceptions and experiences of elder abuse (WHO 2002a).

Throughout these different types, we can distinguish further between intentional or unintentional abuse. The latter suggests that the perpetrator is not always aware of his or her behaviour and of the possible threats to the older person's well-being but which may nonetheless be considered as abuse or neglect, whereas the former indicates some intent to cause harm to an individual (and awareness that his or her action will result in this occurrence).

\section{Research goal}

This article attempts to provide insights into the research designs and research methods used to measure the extent and prevalence of different categories of elder abuse.

The research undertaken as part of this study addressed three key questions:

1. What is the conceptual and theoretical background of existing prevalence studies of abuse and neglect against older people?

2. What is the methodological approach taken and which empirical research methods were put into practice?

3. What are the prevalence rates of elder abuse in different European countries?

\section{Research methodology}

\section{Research framework}

This research is part of the Prevalence study of Abuse and Violence against Older Women (AVOW) which was funded by the EU's Daphne III programme concerning violence against women and children. The AVOW study aimed to provide knowledge about the prevalence of 
AVOW living in the community, in five European countries (Austria, Belgium, Finland, Lithuania and Portugal) through a multi-country empirical study. For the purposes of the literature review, however, all information about the prevalence studies of elder abuse and their methodologies was included in the review, and no initial distinction was made on the basis of gender. Hence, this article focuses on all home-dwelling elders, throughout Europe. Institutional abuse was excluded for the purposes of this research.

\section{Literature collection}

A comprehensive literature search was conducted during the summer of 2009, which followed a stringent search and analysis strategy (e.g. Räty and Aro 2005). Inclusion criteria were developed which determined whether the literature would be included in the review or not. This review focused on studies asking general population samples of older people about the prevalence of abuse. Consequently, it did not concern specific populations, such as impaired or dependent older people. Next, we included primary research reporting prevalence rates of elder abuse from a European country. We did not include studies reporting lifetime abuse, information from meeting abstracts nor oral presentations. Elder abuse needed to be assessed by older people themselves, and research reporting information from caregivers and/or professionals was excluded. No restrictions on the publication date or period were defined, although most studies originate from recent decades.

Based on those inclusion criteria, the following keywords for the literature search were derived:

- abuse, violence, neglect, mistreatment, maltreatment, victimisation, victims, domestic violence, intimate violence, physical abuse, emotional abuse, sexual abuse, economic abuse, financial abuse, medical abuse;

- domestic, family, home, community-dwelling;

- older people, old people, elder, elderly, older, old age(d), aged, seniors;

- prevalence, statistics, trends, questionnaire, survey, measurement (instrument).

For the search in the native languages of the researchers, all keywords were translated. These keywords were found to be appropriate and used as search terms in different national and international databases. The keyword search was put into practice by the use of different channels. First, the search started within scientific databases. ${ }^{1}$ Additional to

\footnotetext{
${ }^{1}$ Following databases were consulted: Academic Search Complete, Academic Search Elite, AgeLine, Alcohol and Alcohol Problems Science Database, Applied Social Sciences Index and Abstracts, Central \& Eastern European Academic Source, EBSCOhost, Gerolit, Journals@Ovid LWW Total Access Collection, Medline, Oxford Journals online, Oxford Reference Online: The Premium Collection,
}

the database search, key international researchers were contacted to provide national reports on elder abuse and to check information if/as necessary; a targeted internet search via Google Scholar and Google books was accomplished if necessary. The literature search and selection process was performed by 10 researchers ( 2 for each country participating in the AVOW study). Both scientific researchers in each country synthesised the main findings.

Following this, each literature hit from the search process was analysed in a qualitative way. A brief check list of quality criteria was developed to determine the quality and the appropriateness of the information provided and to ensure consistency of approaches both within and across research teams:

- Is the reference a (prevalence) study of violence/abuse?

- Does the study include home-dwelling older people?

- Does the study contain prevalence rates of abuse of home-dwelling older people?

- Was the study undertaken at least in one of the European countries?

If it was possible to answer all questions with 'yes' a full review of the literature item was carried out provided the full text was available. Only those articles and studies, which have come through the quality assessment, have been fully reviewed.

\section{Results}

Tables 1 and 2 provide an overview of the literature on prevalence studies on elder abuse or studies that provide some useful information about the extent of elder abuse, found and reviewed for each European country. In total, 19 prevalence studies have been found, throughout 10 European countries: Belgium, Czech Republic, Finland, Germany, Greece, Portugal, Spain, Sweden, The Netherlands, and UK. Tables 1 and 2 summarise for example, information about age range, response rate, data collection methods and answers 5 questions assessing the quality of the prevalence studies. These five questions were:

1. Was probability sampling used to identify possible respondents?

2. Was the abuse measure used reliable?

3. Was the abuse measure used valid?

Footnote 1 continued

the institutional repositories of five Portuguese universities: Minho, Porto, Coimbra, Aveiro and Lisboa. PsychInfo, PsychArticles, PsyndexPLUS, ProQuest, Sociological Abstracts, Social Science Citation Index, Social Sciences Full Text, Social Services Abstracts, Sozialwissenschaften (OLC-SSG), Web of Sciences, WiSo-Social Sciences. 


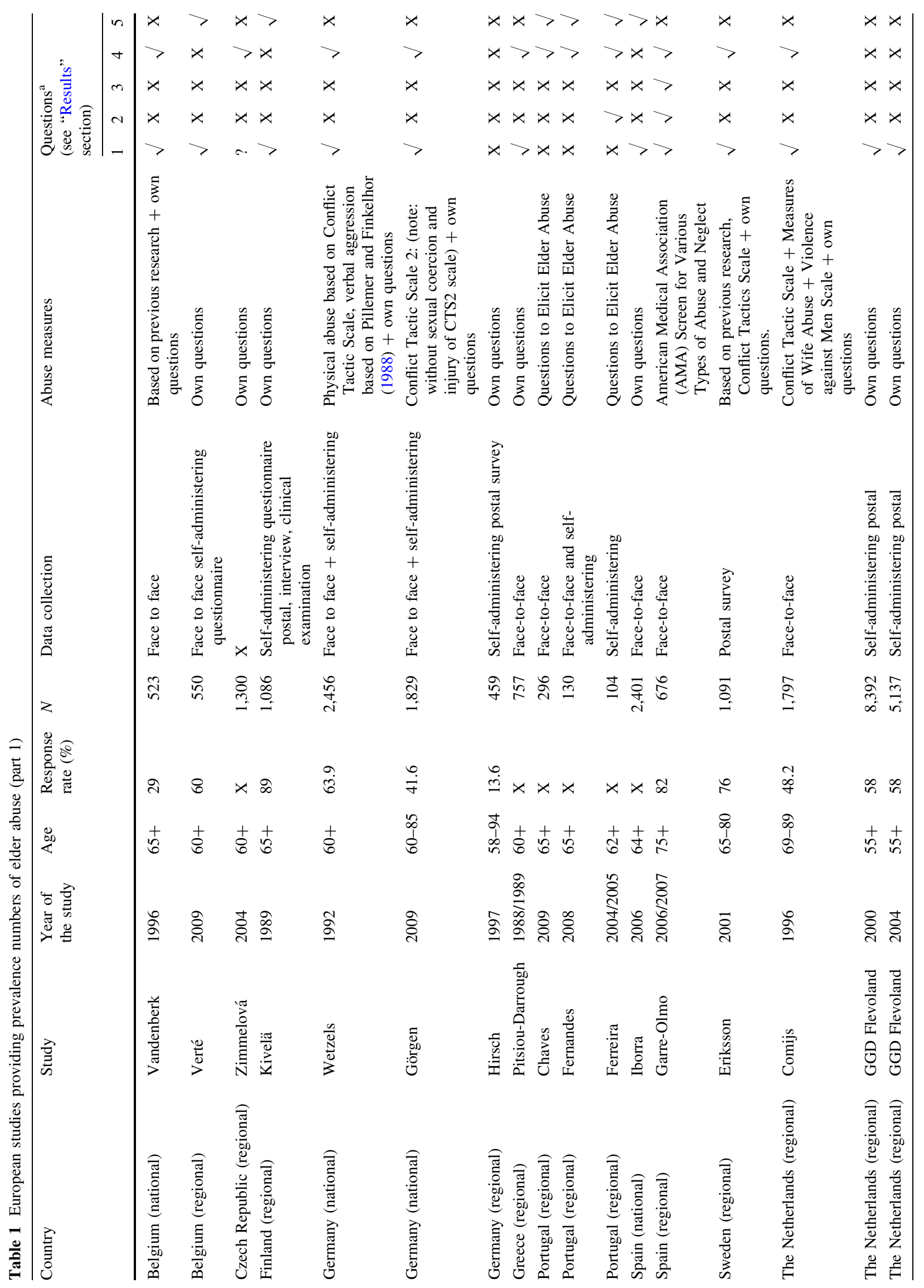




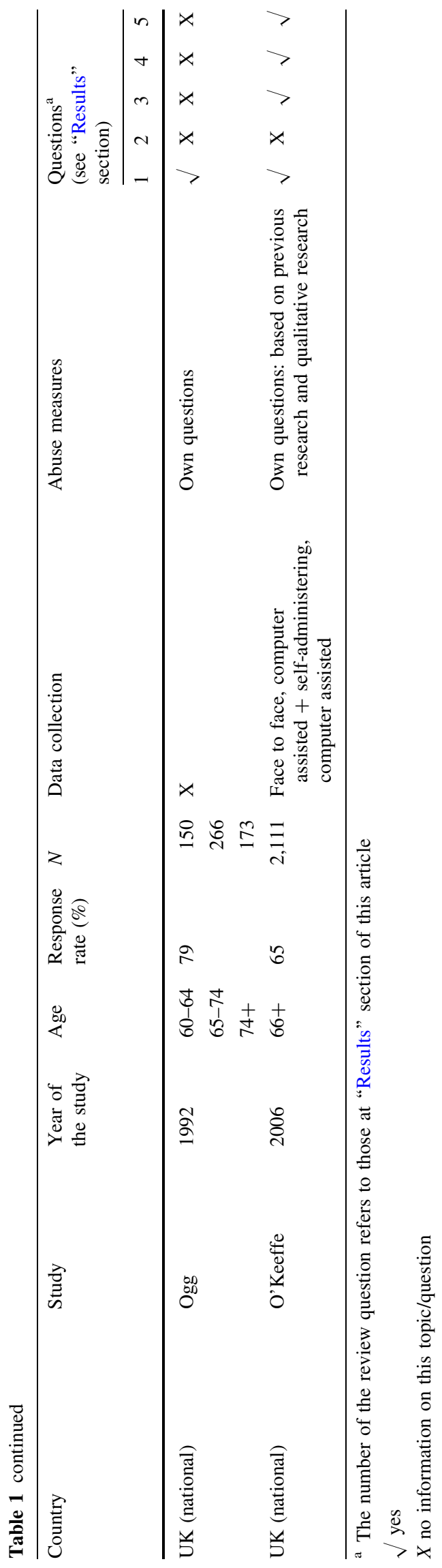

4. Was every type of abuse measured by several items?

5. Have dementia-related disorders been considered?

Prevalence rates of elder abuse

Worldwide, the WHO (2002b) concludes that populationbased surveys have shown that between 4 and $6 \%$ of older people experience some form of abuse in their homes and that mistreatment in institutions may be more extensive than generally believed (WHO 2002b). However, our review of the literature shows considerably larger differences (see Tables 1, 2). The global prevalence rates of home-dwelling elders consists of broad ranges, varying from $0.8 \%$ for elders aged 65 years or more (Iborra 2008) in Spain to $29.3 \%$ among older adults aged 75 years or more (Garre-Olmo et al. 2009 also in Spain) with all kinds of differences in between.

However, making a wholesale but dry inventory does not yield any extra information. The question of why these prevalence rates are so different, not only between but also within countries, is more interesting. In order to consider this further, we need to explore such issues as how elder abuse was measured, which conceptual differences can be noticed, incorporating different categories of abuse in the questionnaire, which methods were used, how the sample was composed and so forth.

How is elder abuse measured?

Results demonstrate that differences in the definition of mistreatment and moreover how elder abuse is measured and constructed can influence the prevalence rates found in a study. Differences in the choice of measurement instrument, in the cut-off used in analyses, when to speak of elder abuse, and reliability and validity are discussed.

\section{Choice of measurement instrument}

Depending on the author's concept and definition of violence or abuse, the items included in the survey instruments used vary greatly. Measurement of abusive behaviour is often based on the study of Pillemer and Finkelhor (1988) and on that of Podnieks (1992). Publications that cited these early studies have operationalised three main areas of abusive behaviour in their studies, namely physical, verbal and financial abuse (e.g. Ogg and Bennett 1992, UK). Another operationalisation often used is the Conflicts Tactics Scale, which is a widely used method of identifying intimate partner violence, with a specific version for recognising child abuse (Straus 1979, 1987, 1996). Several authors used the original CTS or an adapted version (e.g. Comijs et al. 1998, the Netherlands). A further measurement instrument, which 


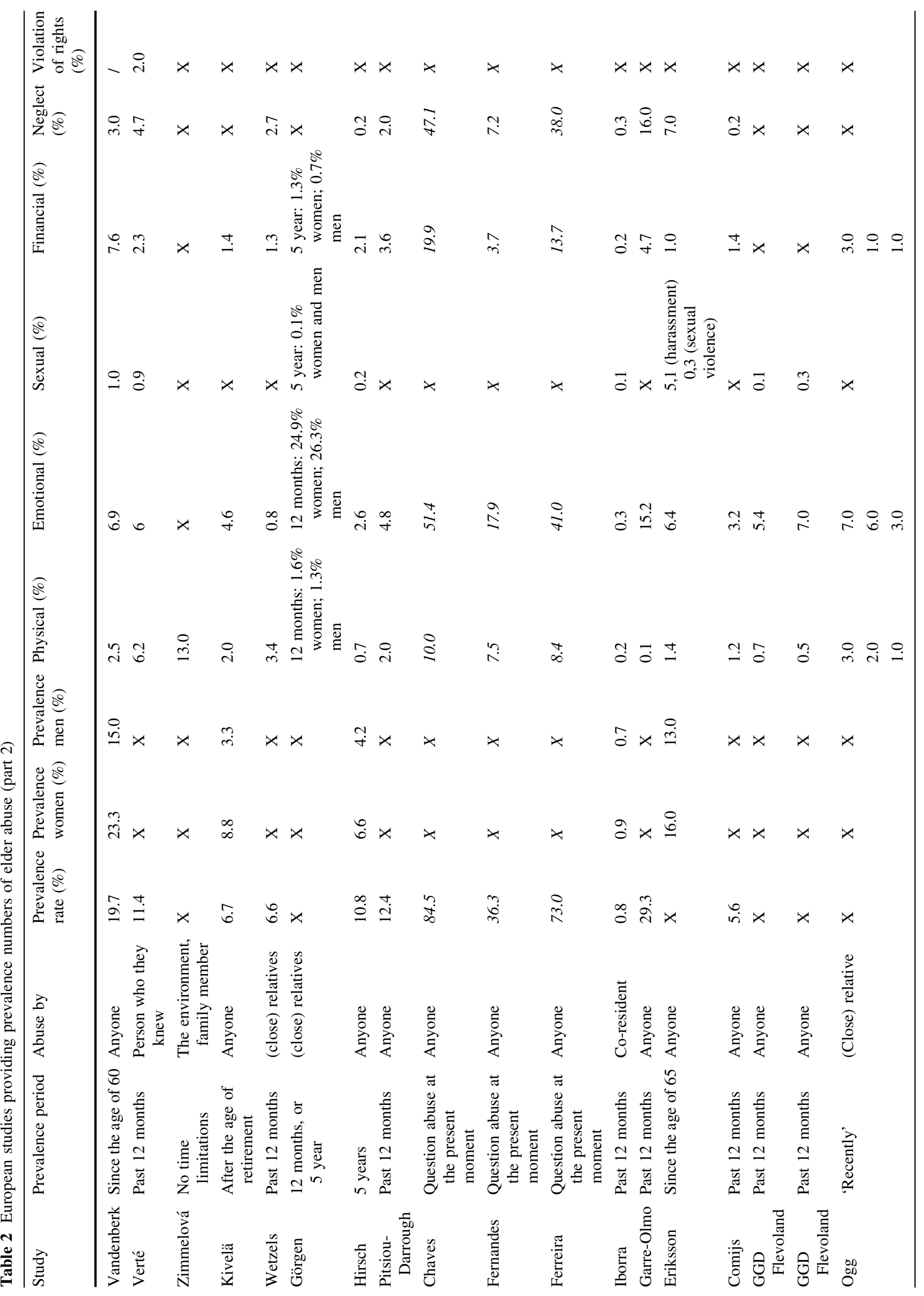


is currently used, is the 'questions that elicit elder abuse' tool (QEEA). This instrument uses 15 specific questions to determine whether abuse is occurring (Carney et al. 2003). If one considers elder abuse as from one positive response to at least one indicator, then the percentages are very high (up to $84.5 \%$ ) (Chaves et al. 2010, Portugal) whereas other scales employ other cut-off points.

\section{As from when to speak of elder abuse}

In constructing elder abuse, Garre-Olmo et al. (2009) in Spain excluded cases with lower scores than 16 to avoid low reliability. However, the Portuguese studies did not undertake such actions, and consequently report these very high prevalence rates. Because of the possibility to mislead readers, the percentages of the studies using the QEEA instrument are put in italics in the enumeration in Table 2. According to our group, only relative place, and relative importance should be taken into account. Another example is the study of Comijs et al. (1998). Those authors used specific cut-off scores for neglect and verbal aggression. Both of these forms needed to happen 10 times in the previous year to be classified as 'abuse'. Physical and financial abuse were both categorised as 'abuse' as soon as an instance occurred at least once in the previous year. This could be a possible explanation why the prevalence rate in the Netherlands as measured by Comijs et al. (1998) is far lower than the prevalence of elder abuse in Belgium as measured by Vandenberk et al. (1998). Similarly, the UK study undertaken by O'Keeffe et al. (2007) used similar cut-off points to Comijs et al. (1998) and obtained lower prevalence rates, although with some variability depending on differing operationalisation of the next factor, namely, that of the relationships between victim and perpetrator.

\section{Relationship: victim-perpetrator}

As previously stated, an operationalisation of a measurement instrument needs to reflect the definition and concept used. Looking at the questions to measure elder abuse in the European studies, we can detect several differences in conceptualisation of relationships, which affects the prevalence rate of elder abuse. For example Iborra (2008, 0.8\%) only measured elder abuse 'by someone living in the same house'. On the other hand, Garre-Olmo et al. (2009, 29.3\%) asked whether the respondents encountered elder abuse 'by anyone'. Likewise, in the most recent UK study, abuse by a family member, close friend or care worker (i.e. those in a traditional relationship involving expectation of trust) yielded a different prevalence rate than that reported when the 1-year prevalence of mistreatment was broadened to include incidents involving neighbours and acquaintances. Between these two situations, the overall prevalence increased from 
$2.6 \%$ for the 'close relationship' to $4.0 \%$ when the wider set of relationships was included (O'Keeffe et al. 2007).

\section{Prevalence period}

Significant differences and variation in the operationalisation of abusive behaviour are also apparent when considering the time periods covered by studies. Four studies examine elder abuse at the present moment or recently (e.g. Ogg and Bennett 1992, UK), most of the researchers $(N=10)$ question elder abuse from the previous 12 months (e.g. GarreOlmo et al. 2009, Spain; O'Keeffe et al. 2007, UK; PitsiouDarrough and Spinnelis 1995, Greece), two studies consider the previous 5 years (Hirsch and Brendebach 1999, Germany), and another study looks back to the time since the respondents were at the age of 60 years (Vandenberk et al. 1998, Belgium) or 65 years (Eriksson 2001, Sweden), although the non-specific age reference 'since the age of retirement' was used in one Finnish study (Kivelä et al. 1992, Finland). Furthermore, Zimmelová (2006, Czech Republic) uses no explicit time limitations to question elder abuse.

\section{Reliability and validity}

The literature review demonstrates that most studies improvise questions and do not appear to (or do not report that they) validate their measurement instruments. 15 studies out of the 19 included in this review use their own questions, and only one of them provides information on face validity. None of the other studies report information on reliability or validity.

\section{Different categories of abuse}

Considering the different types of elder abuse, we can establish a more nuanced picture. Notwithstanding this, not all researchers incorporate all the different types of elder abuse in their studies. Physical abuse is questioned/examined in all previous research studies found $(N=19)$. Next, psychological abuse was nearly almost always considered $(N=18)$. In 16 studies, financial abuse was incorporated, neglect in 13 , sexual abuse in only nine studies and violation of personal rights was only measured in one study. In general, we notice that the variance in prevalence between the different types is large:

\section{Psychological/emotional/verbal abuse}

In general, psychological abuse is the most common form reported by older people (e.g. Kivelä et al. 1992, Finland; Görgen et al. 2009, Germany). When psychological abuse is researched, in $67 \%$ of cases, this form of abuse was reported most frequently and, in $17 \%$ of cases, second most frequently. Total prevalence rates vary from $0.3 \%$ (Iborra 2008, Spain) to $3.2 \%$ (Comijs et al. 1998, Netherlands) reaching up to $26.3 \%$ of older men (Görgen et al. 2009, Germany).

Neglect

Neglect follows psychological abuse closely: $62 \%$ of the studies which include questions on neglect, assign a first or second ranking place in the forms of abuse which occur most often. However, the range is broad with $0.2 \%$ of elders reporting neglect in the Netherlands (Comijs et al. 1998) while in Spain 16\% of home-dwelling elders reported being neglected (Garre-Olmo et al. 2009).

\section{Physical abuse}

In prevalence research on elder abuse, physical abuse is stated in $16 \%$ of the studies as most frequently occurring, and for $40 \%$ of the studies physical abuse appears in second place. Percentages range from $0.1 \%$ of cases (GarreOlmo et al. 2009, Spain) up to $6.2 \%$ (Verté and De Donder 2009, Belgium).

\section{Financial/material abuse or exploitation}

According to WHO (2002b), older people are especially vulnerable to economic abuse, in which family or caregivers or others make inappropriate use of the funds, property and resources of elders. Empirical research in Europe does not entirely follow this position, because and on the whole, financial abuse can be considered only as number four of the most often occurring forms of abuse. Whilst in the research by Vandenberk et al. (1998, Belgium) financial abuse occurs most often, this is only the case in this study. In the UK study that reported in 2007, although financial abuse is the second most frequently ranked type, as this follows neglect, it is the highest ranked from of abuse (O'Keeffe et al. 2007). However, the rate of financial abuse in the UK study is small, at $0.7 \%$. Overall, $7.6 \%$ is the highest prevalence rate found within Europe (Vandenberk et al. 1998). The lowest number of this type of abuse is $0.2 \%$ (Iborra 2008, Spain).

\section{Sexual abuse}

When considering quantity, this kind of abuse is found less often. Between $0.1 \%$ of elders (GGD Flevoland 2001 Netherlands), up to $5.1 \%$ of elders report sexual harassment (Eriksson 2001, Sweden). If researchers incorporated questions on sexual abuse, none of them found sexual abuse as the most or the second most common. 
Violation of the constitutional rights (civil rights) of an older person

This is hardly ever measured by researchers. When questions on this topic were included in studies, researchers reported a prevalence rate of $2 \%$ (Verté and De Donder 2009, Belgium).

Methods used to study prevalence rates of elder abuse

Clearly, prevalence rates can differ, due to the inclusion, or exclusion, of different types of elder abuse. Furthermore, prevalence rates may also differ because researchers used different methodologies, including different methods of data collection and measurement tools, as discussed above. However, in this section, we provide an overview of the methods used to examine the prevalence of elder abuse.

\section{Research design}

The great majority of the underlying studies used a onceonly cross-sectional survey design. The Dutch organisation, GGD Flevoland (2005) used a repeated cross-sectional approach that makes the analysis of trends in the Netherlands possible. In addition, there was one cohort study that followed a group of consecutive referrals over time (Kivelä et al. 1992, Finland). Moreover, this study is also the only one which used a mixed-methods approach: combining a cross-sectional design with qualitative interviews.

\section{Sample}

The sampling method, which is most often applied in prevalence studies, is a random or probability selection of the target group. Within this group, simple or multi-stage stratified random samples could be drawn (e.g. Comijs et al. 1998, Netherlands; Vandenberk et al. 1998, Belgium). In Belgium, Verté and De Donder (2009) used a random quota sample using age groups (60-69, 70-79 and 80+). Nevertheless, three studies have used a non-probability convenience sample, and two studies have not stated explicitly which sampling methods were used in their studies. However, only random samples drawn from homedwelling older adults can produce reliable data on prevalence of elder abuse, suggesting that the other six studies cannot confidently be used.

Considering the sample sizes, the review findings show that these can vary between 104 (Ferreira et al. 2009, Portugal) and 8,392 (GGD Flevoland 2001, the Netherlands). Sample sizes need to be large enough, to be able to infer from the sample to the general population. For example, a sample size of 104 is inadequate to make conclusions on prevalence rates in a country.
Although Boyle (1998) uses in his guidelines for prevalence studies a minimal response rate of $80 \%$, only two studies on elder abuse match this criterion. The lowest response rate of $13.6 \%$ is reported by Hirsch and Brendebach (1999, in Germany). When having such a low response rate, one should be very careful in interpreting and using the results of this study. The difficulty of obtaining a high response rate is especially caused by the sensitive nature of elder abuse and the age of respondents. Nevertheless, an adequate response rate is necessary before we can use the article as a qualified epidemiological article on the topic.

\section{Place}

In the 1990s, a number of national prevalence studies were undertaken (e.g. Comijs et al. 1998, the Netherlands; Pitsiou-Darrough and Spinnelis 1995, Greece). In the 2000s, we see new countries interested in examining prevalence of elder abuse: e.g. Spain (Iborra 2008) and the UK (O'Keeffe et al. 2007). However, national attempts still remain scarce, and most studies are conducted on the regional level within countries. Demarcated regions or some municipalities have also been incorporated in the research (e.g. Zimmelová 2006, Czech Republic).

\section{Age}

The specific age group, which is researched, differs from study to study. The question, 'who is an older person' or 'from what age can we speak of older people' is an oftdebated issue. In general, there is a lot of disagreement about the age from which we can classify as 'elders'. Some take the age of 60 as the lower limit, whereas others only start from the age of 65 (e.g. Fernandes and Dionísio 2009). In European research on elder abuse, we notice that two studies target older people living in private households as from the age of 55 (e.g. GGD Flevoland 2005, Netherlands), and six studies include older residents as from the age of 60 (e.g. Wetzels 1995; Wetzels and Greve 1996, Germany). An identical number of studies $(N=6)$ start from the age of 65 when the social construction of pension age and retirement occurs (e.g. Eriksson 2001, Sweden), and one study uses a higher cut-off point, up to the age of 75 (Garre-Olmo et al. 2009, Spain). Not only the lower limit is of importance, but also because researchers sometimes use an upper limit can cause differences in prevalence rates. For example, Eriksson (2001, Sweden) only researches residents until the age of 80 .

\section{Data collection}

The most common data collection methods in empirical social research have been applied in the prevalence studies 
reviewed. Most often, personal face-to-face interviews were accomplished (e.g. Görgen et al. 2009, Germany; O'Keeffe et al. 2007, UK). Following this, face-to-face interviews in combination with self-administered or self-completion parts without computer assistance have also been adopted among others in Belgium (Verté and De Donder 2009) and in Germany (Görgen et al. 2009). Compared to face-to-face interviews, postal surveys were less common (e.g. Eriksson 2001, Sweden). Computer-assisted personal interviews (CAPI technique) were used once, in combination with interviews (O'Keeffe et al. 2007, UK). This methodology proved to be especially useful for sensitive issues such as questions about domestic abuse and neglect, or sexual abuse. We have found no published European study using telephone interviews for older people.

\section{Discussion}

The aim of this phase of the AVOW study was to provide an overview of the state of the art of prevalence research on elder abuse, research designs and methods, instruments and results from a European perspective. Therefore, an extensive literature search was conducted which followed a strict search strategy. In most European countries, however, no prevalence study on elder abuse was found and, consequently, no information about the prevalence currently exists. These countries include Austria, Bulgaria, Cyprus, Denmark, Estonia, France, Hungary, Iceland, Ireland, Italy, Latvia, Lithuania, Grand Duchy of Luxembourg, Malta, Norway, Poland, Romania, Slovakia, Slovenia and Switzerland.

A first conclusion that can be drawn from the available information concerns the different levels of development throughout the European countries. Some countries have a rich history of prevalence research on elder abuse, whereas other countries have just begun to tackle this aspect of the issue of elder abuse and neglect (or indeed the subject as a whole). Since the term 'granny battering' was used for the first time (in 1975 in the UK), a great deal has been done to develop knowledge, information and assistance on this issue. Yet, citing Penhale (2006, p. 116). there is no room for complacency. One of the lacunae concerns reliable numbers of the prevalence rate of elder abuse. Despite some national differences, on the whole there is only limited research exploring the extent to which abuse or neglect of older people occurs in European private households. Research about where, when and how often elder abuse occurs is generally inadequate and inconsistent, or even non-existent.

Second, we can conclude that although the number of studies on elder abuse varies in different European countries, patterns exist in terms of timing: It begins with episodes of studies in 1980s and 1990s, followed by comparatively less attention in 2000s, especially in relation to prevalence. However, we acknowledge a renewed attention to prevalence in a few specific countries in 2000s (e.g. Germany, Spain, and UK) and some smaller scale studies (i.e. not whole country studies, e.g. Czech Republic) in recent years. In particular, in Central Eastern Europe (CEE), research on elder abuse is limited. Poland is the only country from that region, which was involved in research initiatives on elder abuse and neglect in 1990s (Halicka 1995; , some study is currently continuing in that country nowadays as well. Other countries like Czech Republic, Lithuania, Romania, Bulgaria and Slovakia are also making initial steps into the area of domestic and institutional violence of older people. The Czech Republic is the only CEE country that has started with a regional prevalence study. The problem of elder abuse is not properly recognised on academic as well as political and public levels. This has a direct impact both on research funding and the social visibility of the phenomenon (Reingarde and Tamutiene 2009).

Third, there are various differences between countries concerning the history of their efforts and research. Summarising, we perceive the following differences: different definitions of elder abuse studied or explored, different categories of types of elder abuse, different measurements and instruments used, different time frames examined (previous 12 months; since 60 or 65 years; lifetime experience, etc). Furthermore, we also find different populations, different age restrictions, different sampling methods and different research designs used. All these differences make it extremely difficult, if not virtually impossible, to compare results on the prevalence of elder abuse from the different studies undertaken. Owing to these differences, various studies arrive at diverse prevalence rates of abuse. Therefore, generalisation from existing studies is not likely to be possible. This is more so because research is often restricted to a specific city or region. As we have found, countrywide representative studies are relatively uncommon. For instance, in the Eastern European countries no nationwide studies on the prevalence of elder abuse have been detected, and even if a national prevalence study has taken place, there is barely a sequence. For example, the one national prevalence study that has been conducted in Belgium already dates back to 1998 . Up to now, no followup study has been done.

On the whole, however, some consistent conclusions can be formulated. First, the measurement instrument and questions employed to measure elder abuse are of importance. For example, the results demonstrate that it makes a difference whether anyone can be a possible abuser or whether committing abuse requires a pre-existing relationship or whether abuse is merely studied within certain relationships. Incorporating specific possible abusers in the 
questions may determine the prevalence rate obtained. Consequently, studies on elder abuse must pay attention to the effects of including such information in their questions on the prevalence rate of elder abuse. Another point of attention in discussing the measurement instrument concerns the cut-off that researchers use to determine elder abuse. A possible recommendation for further research could be to pay more attention to density and intensity of abuse. Bennett and Kingston (1993, p. 13) developed a typology consisting of a quadrant with four domains of increasing potential danger. To construct this quadrant, the authors differentiated between density and intensity. Density signifies the number of different forms of abuse that an individual has experienced. Older people can suffer from one type of abuse or from multiple forms of abuse. Intensity refers to the combination of frequency and severity. Intense elder abuse happens very frequently or in a very severe form (or forms). This could enrich and nuance the information provided by an 'overall' prevalence rate of elder abuse.

Furthermore, most studies show variation in elder abuse in relation to different types of elder abuse examined. Prevalence figures vary greatly depending on the type of elder abuse that is researched. In general, psychological abuse has the highest prevalence rates, whereas sexual abuse is reported least often. Violation of personal rights is hardly ever researched or linked with issues of elder abuse and neglect.

\section{Limitations of study}

This study had two important limitations, each of which raises questions to be addressed and which can help to complete this literature review. First of all, linguistic limitations are clearly apparent: in some countries, the literature available in English on the subject is either very limited or is non-existent. Since national or local politics and policy play an important role in enhancing or inhibiting research on elder abuse, a large number of studies and research are policy driven and commissioned or executed by national or regional governments. Consequently, reports on elder abuse may well arise in national languages, which is often not available or understandable to international readers. Obviously, when these reports are also not published officially, this further restricts accessibility and makes it harder to determine what is actually happening in those countries, especially when not even a summary is provided in other languages.

Second, there were also some practical barriers. Some reports were not available to the research team, because several databases were not readily accessible. Also some potentially interesting reports of studies were not yet completed when the review was undertaken (e.g. findings from the ABUEL study, an EU-funded multi-country study of elder abuse, were not due for publishing until mid 2010). These findings can shed additional light on the topic of elder abuse and need to be considered in future research.

\section{Future research}

Depending on the research reviewed, between 0.8 and $29.3 \%$ elders report being abused across European countries, but only a small proportion of these individuals are presently known to protective/social services. Some rates are probably an underestimation because of the reluctance of some people to report abuse (Cooper et al. 2008). Oosterlee et al. (2009) estimate that only $20 \%$ of victims are known to one or more organisations, whilst O'Keeffe et al. (2007) estimate that only $3 \%$ of cases are known to the lead agency for adult protection, social services, in the UK. Valid and reliable measurement instruments are needed (Cooper et al. 2008).

\section{Involving elders}

What is 'known' about elder abuse is that, in many cases, it is based on professionals' reports rather than on information from elders themselves. Older people and family caregivers are involved as participants in only a quarter of the research references on family violence that were reviewed for this study. In other words, researchers have investigated elder abuse by involving professionals or by analysing or considering reports of what professionals and personnel have written about elder abuse (in line with Erlingsson 2007). As a result, Erlingsson (2007) calls for more diverse research on elder abuse with a much greater involvement of older people and family members as participants.

\section{Improving methods}

Surveying elders about such a sensitive topic, however, implies that there is a need for a modified questionnaire, research design and adapted data collection methods. If we want to measure the extent of elder abuse, we must search for a 'hidden' population. Moreover, if we want to question people about sensitive topics, such as elder abuse questions, non-response rates are likely to be higher than usual. Due to this bias, elder abuse will likely be underestimated (Lensvelt-Mulders 2008). However, there exist some methods to support and enhance the participation of the target group. Walby and Myhill (2001) for example give some suggestions to improve research about sexual violence towards women: the sampling frame can be enhanced so as to include the marginalised population. An example is adding a link tracing design, to sample hard-to-contact 
populations (Lensvelt-Mulders 2008). In the case of a postal questionnaire, an incremental snowball-sample can be developed to include those age groups which tend to refuse to participate and who may particularly 'hard-toreach'. Furthermore, some standardised methods such as, explaining the need for the research, guaranteeing privacy, confidentiality and anonymity, making the topic salient to a person and so forth remain important as well (LensveltMulders 2008). Nevertheless, it is true that some older people cannot participate in standardised surveys, because their impaired mental capacity or ill health prevents them from participating. For example, most studies have excluded older people suspected of suffering from dementia (e.g. Garre-Olmo et al. 2009, Spain). However, dementia is a specific risk factor of elder abuse. Elders who suffer from dementia are more often victims than elders who do not have the condition (Zimmelová 2006). If people with dementia are excluded from prevalence studies on elder abuse, then we can assume that the genuine prevalence rate of elder abuse is much higher. This issue is of course more difficult to solve than merely refusing to participate.

\section{How to measure elder abuse?}

Numerous instruments exist to measure abuse: these vary in terms of the items included and in the level and frequency of abusive acts considered to constitute elder abuse. However, accurate estimates of elder abuse are vital for service and policy planning in our ageing society (Cooper et al. 2008). In our overview of the European literature, we conclude that studies hardly ever use a substantiated operationalisation. Researchers often reproduce existing measures or invent new ones without providing sufficient methodological account. Moreover, hardly any of the publications discussed objectivity, reliability and validity of the measurement instrument(s) and statistical information is scarce. A poor measurement tool, however, may lead to an inaccurate estimation of the extent of elder abuse. Therefore, we make an appeal to develop an appropriate measurement tool and to validate the instrument, thereby also taking measurement theory and statistical rules into account.

In considerations of future research, we discuss the main objections which are offered in the literature review and offer some directions and guidelines for the development of an accurate instrument. The first issue to be considered is the length of the questionnaire. On the one hand, instruments and questionnaires need a relatively large number of items. For instance, the self-administered instrument (sensitive questions about abuse and violence) of Görgen has 40 pages and the interviewer's questionnaire encompasses 65 pages (Görgen et al. 2006; Görgen and Nägele 2006). On the other hand, the measurement instrument must not be too long and complicated, taking into consideration the age and potential vulnerability of the target group and the likely time and effort needed to complete the task. Accessibility and usability of the questionnaire should be a priority: in particular, with regard to font size, layout, language and time taken to complete the survey. The questionnaire also should be pilot tested by users, that is to say, by the older people themselves.

Second, abuse and neglect are very sensitive topics and difficult to survey with empirical social research techniques. For instance, retrospective questions about the past are often biased by the ability to recall non-positive events (Höpflinger 2009). However, a number of techniques have been developed in recent years to cover this aspect, and the same need to be used more widely (Walby and Myhill 2001).

Third, the judgement of reliability and validity of the measurement (instrument) is a complicated issue (O'Keeffe et al. 2007). O'Keeffe et al. (2007) argue that a good face validity (property of a test intended to measure something) can be achieved by working stepwise, as undertaken in the UK prevalence study. First of all, the instrument was guided by previous research, and questionnaires from existing studies were collected. Second, the study team received feedback on and advice for the instrument from different stakeholder focus groups such as older people, reference and advisory groups to the study. Third, the draft questionnaire was evaluated and amended by means of cognitive interviewing techniques. Finally, a piloting phase followed. The interviewer was fully briefed and the instrument was further adapted following the pilot stage and as a result of cognitive testing. Such efforts, however, require adequate time and resource to complete them satisfactorily.

\section{Cross-national design?}

A valid measurement instrument is one thing; however, comparisons between studies can only take place when this instrument is used and tested in several studies, preferably in different countries. However, this also requires a crossnational design. This is much needed, and has clear implications for the methodology of the research. A common sampling method and common methods of analysis are prerequisites when constructing a cross-national design. This would enable researchers to accurately compare prevalence rates, risk factors, features of perpetrators, and so forth across different countries. We have currently two crossnational studies that have been executed in 2010: ABUEL and AVOW studies. The ABUEL study is a prevalence study of elder abuse, conducted in seven European countries (Germany, Greece, Italy, Lithuania, Portugal, Spain and Sweden) by means of standardised assessment instruments and methods. Second, the AVOW study examined abuse and neglect specifically of older women in Austria, Belgium, Finland, Lithuania and Portugal. However, at the time when 
the literature search was undertaken, neither of the two projects had published data or information on the research results, but these two data sets seem promising for further European research on the prevalence of elder abuse.

Of course, a sole emphasis on personal (universal) indicators is too simplistic: abuse and violence are embedded in structural as well as cultural levels (Hirsch and Brendebach 1999). Who is a victim and who is not a victim is not always easy to detect. All kinds of factors, levels and dynamics do not explain human behaviour but they give an indication of how complex this issue is to determine, particularly cross-nationally and cross-culturally (Cooper et al. 2008). Therefore, a cross-national design can include several culture- or country-specific questions. Nevertheless, individual country questions need to be and ought to be balanced and should not 'overtake' the core set of questions as it will be necessary to demonstrate the robustness of the study to be able to compare findings cross-nationally.

Combating elder abuse requires an integral knowledge and understanding of those patterns and forces that underlie it. As research on elder abuse is still an area quite early in its development, particularly regarding trans-national studies, a great deal of study remains to be done. Previous research has made some noteworthy strides in that direction, but clearly this is a line of inquiry that could be, and deserves to be, pursued more systematically, particularly at pan-European level, and also on international and even global levels.

Acknowledgments The authors are indebted to the European Commission's DAPHNE III programme that has supported and funded the AVOW study. Furthermore, the authors are grateful toMinna Piispa, The National Institute for Health and Welfare (THL), Finland; Helena Ewalds, The National Institute for Health and Welfare (THL), Finland; Ariela Lowenstein, Head Center for Research \& Study of Aging, Department of Masters of Gerontology, University of Haifa, Israel; Rui Dionísio, Psychologist and Nurse, Hospital of Viseu; Isabel Iborra Marmolejo from research coordinator of Queen Sofía Center, Spain; Olga Tóth, Senior Research Fellow, Institute of Sociology, Hungarian Academy of Sciences, Hungary; Ana Luísa Patoleia, Ana Margarida Silva, Carlos Fernandes, Cláudia Chaves, Maria Emília Vergueiro and Rui Dionísio; Gerd Callewaert from the Flemish Reporting Point on Elder Abuse; Dr. Leo Pas, who has been working with Domus Medica; Dr. Nicolas Berg who was involved with CAPAM; and Marie Thérèse Casman from the University of Liège-for providing us with information, overviews, national reports and studies, prevalence figures, and other information on the abuse and mistreatment of older people.

\section{References}

\section{References with an asterisk are prevalence studies of elder abuse included in the literature review}

Action on Elder Abuse (1995) Action on elder abuse's definition of elder abuse. Action on Elder Abuse, London. Bulletin, May/June Baker AA (1975) Granny battering. Mod Geriatr 5(8):20-24
Bakker H, Beelen J, Nieuwenhuizen C (2000) Pain in old age: elder abuse, perspectives for care. NIZW Uitgeverij, Utrecht (in Dutch)

Bennett G, Kingston P (1993) Elder abuse: concepts, theories and interventions. Chapman and Hall, London

Bennett G, Levin S P, Straka S (2002) Missing voices. Views of older persons on elder abuse. Geneva, WHO. http://www.who.int/ ageing/projects/elder_abuse/missing_voices/en/. Accessed 1 February 2010

Boyle MH (1998) Guidelines for evaluating prevalence studies. Evid Based Ment Health 1:37-39

Burston GR (1975) Granny battering. Br Med J 3(5983):592

Carney MT, Kahan FS, Paris BEC (2003) Elder abuse: is every bruise a sign of abuse? Mt Sinai J Med 70(2):69-74

*Chaves C, Ferreira-Alves J, Martins R, Albuquerque C, Pereira A, Andrade A (2010) Signs of elder abuse in the District of Viseu. Psychol Health 25(1):178-184

*Comijs HC, Pot AM, Smit JH, Bouter LM, Jonker C (1998) Elder abuse in the community: prevalence and consequences. J Am Geriatr Soc 46(7):885-888

Cooper C, Selwood A, Livingston G (2008) The prevalence of elder abuse and neglect: a systematic review. Age Ageing 37(2):151-160

Dieck M (1987) Elder abuse in the family context: a topic of research, practice and public information. Z Gerontol 20(5):305-313 (in German)

*Eriksson H (2001) Prevalence study of violence against older women and men in the Umea municipality. Crime Victim Compensation and Support Authority, Umea (in Swedish)

Erlingsson CL (2007) Searching for elder abuse: a systematic review of database citations. J Elder Abuse Negl 19(3/4):59-78

EU (2000) EU charter on human rights. http://www.europarl. europa.eu/charter/pdf/text_en.pdf. Accessed 5 February 2010

*Fernandes C, Dionísio R (2009) Violence on older adults. Unpublished manuscript, University of Coimbra, Portugal (in Portuguese)

*Ferreira-Alves J, Daly J, Sousa M, Ferreira M, Jorgest G (2009) Indicators of domestic elder mistreatment. A study in Portugal day care centers. Unpublished manuscript

*Garre-Olmo J, Plana-Pujol X, López-Pousa S, Juvinya D, Vila A, Vilalta-Franch J (2009) Prevalence and risk factors of suspected elder abuse subtypes in people aged 75 and older. J Am Geriatr Soc 57:815-822

*GGD Flevoland (2001) Seniors in sight: seniorsurvey 2000 Flevoland. GGD Flevoland, Lelystad (in Dutch)

*GGD Flevoland (2005) Seniors in sight: seniorsurvey 2004 Flevoland. GGD Flevoland, Lelystad (in Dutch)

Görgen T, Nägele B (2006) Sexual victimization in old age. Z Gerontol Geriatr 39(5):382-389 (in German)

Görgen T, Herbst S, Rabold S (2006) Crime experiences and experiences of violence in higher age and in domestic care. Interim results of the study "Crime and violence in the lives of old people" (KuGiLaM-Report No. 2). Criminological Institute of Lower Saxony, registered association (KFN) and Federal Ministry for Family Affairs, Senior Citizens, Women and Youth, Hannover (in German)

*Görgen T, Herbst S, Kotlenga S, Nägele B, Rabold S (2009) Crime experiences and experiences of violence in the lives of older people. Summary of major events of a study on risk of older and dependent people. Federal Ministry for Family Affairs, Senior Citizens, Women and Youth, Berlin (in German)

Hagemann-White C (2001) European research on the prevalence of violence against women. Violence Against Women 7(7):732-759

Halicka M (1995) Elder abuse and neglect in Poland. In: Kosberg JI, Garcia JL (eds) Elder abuse: international and cross-cultural perspectives. The Haworth press Inc, New York, pp 157-170

*Hirsch RD, Brendebach C (1999) Violence against the elderly in the family: investigation of the "Bonn HSM-study". Z Gerontol Geriatr 32(6):449-455 (in German) 
Höpflinger F (2009) Retrospective questions-problems and possible strategies. http://www.hoepflinger.com/fhtop/fhmethod1D.html. Accessed 24 October 2009 (in German)

Hörl J, Spannring R (2001) Violence against the elderly. In: Federal Ministry of Social Affairs, Generations and Consumer Protection (ed) Report on abuse in Austria. BMSG, Vienna, pp 305-344 (in German)

Hudson MF (1991) Elder mistreatment: taxonomy with definitions by Delphi. J Elder Abuse Negl 2:1-20

*Iborra M I (2008) Older adults' mistreatment within Spanish families. Foundation of the Valencia Community for the study of violence, Queen Sofía Center, Valencia (in Spanish)

*Kivelä S-L, Köngäs-Saviaro P, Kesi E, Pahkala K, Ijäs M-L (1992) Abuse in old age-epidemiological data from Finland. J Elder Abuse Negl 4(3):1-18

Lensvelt-Mulders GJLM (2008) Surveying sensitive topics. In: de Leeuw ED, Hox JJ, Dillman DA (2008) International handbook of survey methodology. Erlbaum, New York, pp 461-478

* Ogg J, Bennett G (1992) Elder abuse in Britain. Br Med J 305 (6860):998-999

*O'Keeffe M, Hills A, Doyle M, McCreadie C, Scholes S, Constantine R et al (2007) UK study of abuse and neglect of older people. Prevalence survey report. King's College London and National Centre for Social Research, London

Oosterlee A, Vink RM, Smit F (2009) Prevalence of family violence in adults and children: estimates using the capture-recapture method. Eur J Public Health 19(6):586-591

Penhale B (2006) Elder abuse in Europe: an overview of recent developments. J Elder Abuse Negl 18(1):107-116

Penhale B (2008) Elder abuse in the United Kingdom. J Elder Abuse Negl 20(2):151-168

Pillemer KA, Finkelhor D (1988) The prevalence of elder abuse: a random sample survey. Gerontologist 28(1):51-57

*Pitsiou-Darrough EN, Spinellis CD (1995) Chapter 4: Mistreatment of the elderly in Greece. J Elder Abuse Negl 6(3):45-64

Podnieks E (1992) National survey on abuse of the elderly in Canada. J Elder Abuse Negl 4(1):5-58

Räty S, Aro AR (2005) European review protocol for health promotion. A protocol produced by the getting evidence into practice, Strand I. National Public Health Institute (KTL), Helsinki
Reingarde J, Tamutiene I (2009) AVOW literature review: Bulgaria, Estonia, Czech Republic, Latvia, Lithuania, Poland, Romania, Slovakia and Slovenia. http://www.thl.fi/avow. Accessed 1 February 2010

Straus MA (1979) Measuring intra-family conflict and violence: the Conflict Tactics (CT) Scales. J Marriage Fam 41(1):75-88

Straus MA (1987) The Conflict Tactics Scales and its critics: an evaluation and new data on validity and reliability. New Hampshire University, Durham

Straus MA (1996) The revised Conflict Tactics Scales (CTS2). Development and preliminary psychometric data. J Fam Issues 17(3):283-316

Strümpel C, Hackl C (2008) Breaking the taboo: European report. http://www.preventelderabuse.eu/european/1/2/6/1/get.aspx. Accessed 1 February 2010

UK Department of Health and Home Office (2002) No secrets: guidance on developing and implementing multi-agency policies and procedures to protect vulnerable adults from abuse. http://www.dh.gov. uk/en/Publicationsandstatistics/Publications/PublicationsPolicy AndGuidance/DH_4008486. Accessed 1 February 2010

*Vandenberk A, Opdebeeck S, Lammertyn F (1998) Violence and fear of crime among older people. Ministerie van Tewerkstelling en Arbeid en Gelijke kansen/Leuven, KUL, Brussel (in Dutch)

*Verté D, De Donder L (2009) AVOW literature review Belgium, Cyprus, France, Grand Duchy of Luxembourg, Italy and the Netherlands. http://www.thl.fi/avow. Accessed 1 February 2010

Walby S, Myhill A (2001) New survey methodologies in researching violence against women. Br J Criminol 41(3):502-522

*Wetzels P (1995) About the use of facilities of the victims. Results of a national representative victim survey. Criminological Institute of Lower Saxony, registered association (KFN), Hannover (in German)

*Wetzels P, Greve W (1996) Older people as victims of family violence. Results of a German victimization survey. Z Gerontol Geriatr 29(3):191-200

WHO (2002a) The Toronto declaration on the global prevention of elder abuse. WHO, Geneva

WHO (2002b) The world report on violence and health. WHO, Geneva

*Zimmelová P (2006) Domestic violence and seniors. J Health Sci Manag Public Health 7(1):59-66 